\title{
Globe
}

Revue internationale d'études québécoises

\section{Jacques Keable, Les folles vies de La Joute de Riopelle : les mésaventures de l'art public, Montréal, Lux, 2009}

\section{Annie Gérin}

Volume 13, numéro 1, 2010

Culture et relations internationales

URI : https://id.erudit.org/iderudit/044645ar

DOI : https://doi.org/10.7202/044645ar

Aller au sommaire du numéro

Éditeur(s)

Globe, Revue internationale d'études québécoises

ISSN

1481-5869 (imprimé)

1923-8231 (numérique)

Découvrir la revue

Citer ce compte rendu

Gérin, A. (2010). Compte rendu de [Jacques Keable, Les folles vies de La Joute de Riopelle : les mésaventures de l'art public, Montréal, Lux, 2009]. Globe, 13(1),

172-174. https://doi.org/10.7202/044645ar d'utilisation que vous pouvez consulter en ligne.

https://apropos.erudit.org/fr/usagers/politique-dutilisation/ 
che, mais également - et comment éviter la référence à la thématique de Boisclair? J'y renonce... - dans sa perspective d'ensemble qui renouvelle le regard que nous posons sur le corpus national.

Dans un contexte intellectuel où la littérature est parfois considérée comme une manifestation culturelle parmi tant d'autres, on ne peut que se réjouir qu'un ouvrage de cette envergure livre une réflexion approfondie sur des enjeux esthétiques de la poésie québécoise.

Lucie Picard

Chercheure indépendante

\section{Jacques Keable}

Les folles vies de La Joute de Riopelle:

les mésaventures de l'art public,

Montréal, Lux, 2009.

Le 18 mars 2002, jour des funérailles de Jean-Paul Riopelle, un ami de l'artiste se présente devant les micros et les caméras de la télévision et, la gorge nouée par l'émotion, lui fait publiquement ses adieux devant une foule assemblée. C'est à ce moment que les Québécois apprennent, à leur grande surprise, le projet de délocaliser du quartier Hochelaga-Maisonneuve de Montréal une ouvre majeure de Riopelle, installée à proximité du Stade olympique un quart de siècle plus tôt, à l'occasion des jeux de 1976.

L'œuvre dont il est question, c'est La Joute. L'ensemble sculptural de 29 morceaux - il s'agit en fait d'une fontaine monumentale en bronze se trouve alors dans un état de détérioration avancée. Pratiquement oubliée du Musée d'art contemporain de Montréal, qui en est propriétaire au nom du ministère de la Culture, des communications et de la condition féminine, et de son hôte, la Régie des installations olympiques, La Joute est privée d'eau, partiellement rouillée et enfermée derrière des murs érigés après son installation et qui la soustraient aux regards des passants. La fontaine, dont la valeur est estimée à cinq millions de dollars malgré son état de dégradation, doit être déplacée vers un nouveau lieu, un lieu qui posera toutes sortes de défis techniques et qui occasionnera des coûts impressionnants: un nouveau square aménagé dans le Quartier international des affaires de Montréal, entre la Caisse de dépôt et placement et le Palais des congrès, sur le toit de l'autoroute Ville-Marie. 
Dès le lendemain des funérailles, les journaux réagissent avec indignation à cette délocalisation qui n'allait pas de soi. Au fil des jours, le public apprend que ce qui semble être un complot se tramait depuis plusieurs années dans les couloirs du Parlement québécois et aux tables d'un restaurant fréquenté par la gent politique et économique, loin des oreilles de l'artiste, des professionnels de l'art, des riverains de l'œuvre et des autres intéressés. Les opposants à la délocalisation interprètent donc celle-ci comme une attaque dirigée contre la population du quartier Hochelaga-Maisonneuve qui vise à la déposséder d'une pièce majeure du patrimoine artistique québécois, un rapt.

La communauté s'organise et se mobilise, rassemblant des partenaires inattendus provenant des groupes populaires, des organismes nationaux et des milieux politiques, ainsi que de nombreux professionnels de l'art et artistes. Elle se demande pourquoi le gouvernement préfere déménager à très grands frais une œuvre qui aurait pu être rénovée sur place. En effet, pour les mêmes coûts, en plus de la restauration de La Joute, une œuvre nouvelle aurait pu être produite pour le Quartier international des affaires, fournissant à un artiste contemporain une commission bien rémunérée et la rare occasion de travailler à grande échelle sur une place toute neuve. Les intéressés constatent d'ailleurs qu'on a fait fi d'une certaine convention, d'un consensus implicite qui veut qu'un lieu public nouveau appelle une œuvre d'art imaginée pour celui-ci et qui formera une histoire avec lui au fil des ans.

Comme le remarque l'historien de l'art François-Marc Gagnon, qui signe la préface des Folles vies, il s'agit d'une "affaire qu'on pourrait croire, à première vue, du ressort de la seule histoire de l'art mais qui, en réalité, a touché toute la population d'un quartier défavorisé, qui a des répercussions sur la manière dont nos élus traitent les dossiers culturels et qui nous fait prendre conscience du chemin qu'il nous reste encore à parcourir avant de se retrouver dans une véritable démocratie» (p. 11). En effet, de cet imbroglio ressortent toutes sortes de questions: Quel fut le rôle dans cette affaire des politiciens, dont Bernard Landry, Louise Harel et Lucien Bouchard? Quel fut celui des mécènes donateurs, des responsables du développement du Quartier international des affaires, des journalistes et des nombreux autres intervenants? Quels registres d'arguments ont été employés pour justifier et opposer le déménagement? Et quels étaient les enjeux réels - politiques, économiques et culturels - entourant la délocalisation de La Joute?

En plus de relater les événements qui entourent la création, l'installation et la subséquente délocalisation de La Joute, Les Folles vies de La Joute de Riopelle produit l'autopsie de la lutte menée par SOS La Joute 
(comité citoyen formé en 2002, et dont Jacques Keable était un membre actif) dans le but de conserver l'œuvre dans le quartier HochelagaMaisonneuve. Si son constat est à la fois triste, mordant et plein d'humour, l'ouvrage de Keable sert aussi d'introduction aux enjeux de l'art public pour un lecteur peu initié, car il souligne particulièrement les "mésaventures de l'art public", comme l'indique le sous-titre.

En effet, avant de plonger son lecteur dans la polémique, Keable brosse un portrait soigné des enjeux généraux et des intervenants principaux du champ de l'art public. Au fil des pages, le lecteur rencontre donc d'autres cas de figure québécois et canadiens, dont plusieurs peu connus du grand public. Certains termes importants et pourtant souvent utilisés de façon approximative y sont définis avec clarté : patrimoine, public, art public, politique du $1 \%$, etc. Les questions pratiques et éthiques qui minent le champ y sont aussi développées et débattues: la conservation des œuvres, l'appropriation des œuvres par la communauté, la médiation culturelle dans l'espace public, l'attitude qu'a notre société envers l'art public, etc. Finalement, la conclusion pose la question du rôle du public (ou de son absence) dans l'art public, une réflexion qui aurait aussi pu s'ouvrir plus largement sur la question de l'instrumentalisation des arts dans la culture contemporaine. C'est effectivement de ce côté que se dirige ultimement l'affaire La Joute.

Ancrée dans une recherche d'archives minutieuse et une trentaine d'entrevues, dont plusieurs auprès de personnes qui sont intervenues directement dans le dossier, l'analyse que nous en fait le journaliste Jacques Keable - de sa plume redoutable - est autant perçante que surprenante. D'ailleurs, l'auteur ne s'empêche pas de jouer le rôle d'éditorialiste, de commenter avec humour et lucidité les événements et les propos de différents intervenants. Truffé de conflits d'intérêts, de corruption, d'intrigues loufoques et d'événements rocambolesques, ce livre qui tient son lecteur en haleine éclaire d'une lumière vive les enjeux qui s'entrelacent au cour de la polémique qui se développa autour de la délocalisation de La Joute de Riopelle.

Annie Gérin

Université du Québec à Montréal 